\title{
VÍTIMAS FATAIS E ANOS DE VIDA PERDIDOS POR ACIDENTES DE TRÂNSITO EM MINAS GERAIS, BRASIL
}

\author{
Fatal traffic accidents victims and potential years of life lost in Minas Gerais, Brazil \\ Víctimas fatales y años de vida perdidos por accidentes de tráfico en Minas Gerais, \\ Brasil
}

Fernanda Carolina Camargo ${ }^{1}$

Helena Hemiko Iwamoto²

\section{RESUMO}

Estudo objetivou analisar o perfil das vítimas fatais pelos acidentes de trânsito e quantificar o impacto desses óbitos através dos anos potenciais de vida perdidos (APVP), em Minas Gerais. Utilizou-se de abordagem epidemiológica por registros do Sistema de Informação de Mortalidade do Departamento de Informática do Sistema Único de Saúde. Entre 1996 e 2007, ocorreram 38.395 óbitos, média anual de 17,61 óbitos/100.000 habitantes. Foram 8.894,46 APVP/100.000 habitantes, perfazendo 43,24 APVP por óbito. Homens, entre 20 e 59 anos, foram as maiores vítimas fatais. Essa mortalidade apresentou ascendência entre os idosos. De forma geral, acidentes de trânsito resultam de desarranjos na infraestrutura urbana, comportamento arriscado de condutores e pedestres e ineficiências na regulação/fiscalização do tráfego. É complexo o seu impacto no setor saúde, principalmente pela perda de pessoas em idade produtiva. Perante os resultados apresentados, espera-se contribuir para o fomento de novas possibilidades de enfrentamento desse agravo.

Palavras-chave: Enfermagem em saúde pública. Acidentes de trânsito. Mortalidade. Anos potenciais de vida perdidos.

\begin{abstract}
Study aims to analyze the profile of fatal traffic accidents victims and quantify the impact of these deaths by the potential years of life lost (PYLL), in Minas Gerais, Brazil. We used an epidemiological approach for records of the Mortality Information from the Department of the Brazilian Unified Health. Between 1996 and 2007, there were 38.395 deaths, an annual average of 17.61 deaths per 100.000 inhabitants. There were 8894.46 PYLL per 100,000 inhabitants, performing 43.24 PYLL per death. Men, 20 to 59 years old, were the main casualties. This mortality ascended among the elderly. Generally, traffic accidents result from disorders in urban infrastructure, risky behavior of drivers and pedestrians, inefficiencies in the regulation/supervision of traffic. It is Complex, the impact on the health sector, mainly the loss of people of working age. Facing the results presented, it is expected to contribute to the development of new possibilities for confronting this disease
\end{abstract}

Keywords: Public Health Nursing. Mortality. Accidents, Traffic. Potencial Years of Life Lost.

\section{Resumen}

El estudio tiene como objetivo analizar el perfil de las víctimas fatales por accidentes de tráfico y cuantificar el impacto de estas muertes a través de los años potenciales de vida perdidos (APVP), en Minas Gerais. Se utilizó de abordaje epidemiológico por registros del Sistema de Información de Mortalidad del Departamento de Informática del Sistema Único de Salud. Entre 1996 y 2007 se produjeron 38.395 muertes, un promedio anual de 17,61 muertes por cada 100.000 habitantes. Fueron 8.894,46 APVP por cada 100.000 habitantes, lo que representa 43,24 APVP por cada muerte. Hombres, de 20 a 59 años, fueron las principales víctimas. Esa mortalidad presentó ascendencia entre los ancianos. En general, accidentes de tráfico resultan de problemas en la infraestructura urbana, comportamiento de riesgo por parte de los conductores y peatones e ineficiencias en la regulación/fiscalización del tráfico. Complejo es su impacto en el sector de la salud, principalmente por la pérdida de personas en edad productiva. Ante los resultados presentados, se espera contribuir para el fomento de nuevas posibilidades de enfrentamiento de ese agravo.

Palabras clave: Enfermería en Salud Pública. Accidentes de Tránsito. Mortalidad. Años Potenciales de Vida Perdidos.

\footnotetext{
'Enfermeira. Mestre em Atenção à Saúde pela Universidade Federal do Triângulo Mineiro (UFTM). Uberaba - MG. Brasil. Email: fernandaccamargo@yahoo.com.br; ${ }^{2}$ Enfermeira. Doutora em Enfermagem Fundamental pela Escola de Enfermagem de Ribeirão Preto da Universidade de São Paulo. Professora Adjunta da Universidade Federal do Triângulo Mineiro (UFTM). Uberaba - MG. Brasil. Email: helena.iwamoto@gmail.com
} 


\section{INTRODUÇÃO}

No Brasil, a organização social atual impõe para a atenção à saúde uma ampliação de suas ações para além das doenças transmissíveis. Novas epidemias emergem nesse cenário, principalmente aquelas relacionadas ao modo de viver da coletividade urbana. ${ }^{1-3}$ Nesse contexto, destacam-se os acidentes de trânsito. ${ }^{1,2}$

Os números resultantes dos acidentes de trânsito são alarmantes tanto para nível nacional como internacional. Há projeções de que seus custos sociais sejam de $1 \%$ do Produto Interno Bruto (PIB) para os países em desenvolvimento e de até $2 \%$ para os países desenvolvidos. ${ }^{2,4}$ Vale destacar que o Brasil ocupa no ranking mundial a quinta posição quanto à mor talidade por esse agravo. ${ }^{4}$ Adiciona-se aos impactos negativos dos acidentes de trânsito, para o Brasil, o valor do custo médio de tratamento das vítimas, $25 \%$ maior do que o custo médio para uma internação geral, e, ainda, $6 \%$ das incapacidades físicas decorrem desse agravo. ${ }^{2,4}$

De forma geral, os acidentes de trânsito têm como fator predisponente a elevação da frota de veículos circulantes, amparada pelo aumento populacional, pelas deficiências dos transportes públicos e pelas necessidades de deslocamentos, cada vez mais longos e mais velozes. Contribui para a perpetuação desse agravo a precariedade da infraestrutura urbana, em que os sistemas viários e de planejamento urbano pouco acompanharam, em seu desenvolvimento, as necessidades de tráfego contemporâneas. Em geral, as cidades estão carentes de estruturas físicas e de sinalização que venham a auxiliar a segurança viária.-7

Outro fator agravante para a perpetuação dos acidentes de trânsito está na adoção de comportamentos de risco pelos condutores e pelos próprios pedestres. Esses comportamentos relacionam-se ao desrespeito perante a sinalização de trânsito, a condução de veículos em alta velocidade e mediante o uso abusivo do álcool e outras drogas. Além disso, ocorrem situações de treinamento inadequado dos condutores, no que se refere às técnicas e atitudes para direção defensiva, resultando em despreparo na educação dos cidadãos para o direito social de ter um trânsito em condições seguras. ${ }^{7,8}$

São apontadas como fator para a perpetuação desses acidentes as fragilidades do controle do trânsito perante os seus aspectos legislativos. Da mesma forma que existe a impunidade mediante as infrações de trânsito, alguns dispositivos de controle do comportamento dos condutores e dos pedestres apresentam resultados apenas sobre a ação ostensiva de fiscalização, seja pelo policiamento ou de mecanismos eletrônicos. Esses conjuntos de fatores resultam no expressivo aumento da vitimização pelos acidentes de trânsito que incluem ferimentos graves, incapacidades e até 0 óbito. ${ }^{5-8}$

Diante dessa realidade, os acidentes de trânsito e suas vítimas apresentam-se como um problema complexo e multifacetado ao setor saúde, haja vista que o setor saúde tem sido o ponto de convergência aos danos provocados por esse agravo. Para o seu enfrentamento, diante das perdas de potencial de vida das vítimas, as unidades de saúde e seus profissionais têm sido requisitados para reorientarem suas práticas assistenciais. ${ }^{2,5-8}$

Os procedimentos em saúde, incluindo a prática de enfermagem, antes estabelecidos pelo cuidado às enfermidades orgânicas, devem estar apoiados em ações capazes de predizer, controlar ou eliminar o agravo e seus fatores determinantes. ${ }^{2,3}$

Nesse sentido, as abordagens epidemiológicas apresentam-se como ferramentas facilitadoras na compreensão do agravo, por contribuírem com a definição dos fatores de risco para sua ocorrência e com a identificação dos grupos sociais de maior vulnerabilidade. Além disso, essas análises possibilitam quantificar o impacto desse agravo em âmbito social, por meio do cálculo de indicadores de saúde. ${ }^{3,9}$

Vale ressattar que os indicadores de saúde são medidas-sínteses preditivas, amparadas em dados válidos e confiáveis. Referem-se a diferentes aspectos das condições de saúde de determinada população, pelos quais podem ser estabelecidos seus perfis de adoecimento. São exemplos desses indicadores os Coeficientes de Mortalidadee os Anos Potenciais de Vida Perdidos (APVP). ${ }^{9}$

Neste contexto, há o entendimento de que abordagens epidemiológicas contribuem na elaboração de propostas de intervenções ampliadas para o enfermeiro, que enfatizam as práticas educativas, a ação multidisciplinar e intersetorial, a mobilização comunitária, visando o enfrentamento de diversos agravos, incluindo os acidentes de trânsito. ${ }^{3}$ Por esta razão, o presente estudo tem como objetivo analisar o perfil das vítimas fatais pelos acidentes de trânsito equantificar o impacto desses óbitos na população por meio dos anos potenciais de vida perdidos.

\section{MÉTODO}

Trata-se de um estudo descritivo, quantitativo de abordagem ecológica, através das informações registradas em banco de dados do Sistema de Informação de Mortalidade (SIM), disponível no Departamento de Informática do Sistema Único de Saúde (DATASUS), acessadas pelo endereço eletrônico uww.datasus.gov. $b^{10}$, para o período de 1996 a 2007, em Minas Gerais. 0 limite temporal proposto considera a atualidade dos dados disponíveis no DATASUS, conforme a Classificação Internacional de Doenças - $10^{a}$ Revisão - (CID-10). ${ }^{11}$

Foram identificadas como vítimas fatais por acidentes de trânsito aquelas definidas pelo grande grupo de causas externas Acidentes de Transporte [V01-V99], composto de óbitos de: Pedestre traumatizado em um acidente de transporte [V01-V09]; Ciclista traumatizado em um acidente de transporte [V10-V19]; Motociclista traumatizado em um acidente de transporte [V20V29]; Ocupante de triciclo motorizado traumatizado em um acidente de transporte [V30-V39]; Ocupante de um automóvel traumatizado em um acidente de transporte; [V50-V59] Ocupante de uma caminhonete traumatizado em um acidente de transporte [V40-V49]; Ocupante de um veículo de transporte pesado traumatizado em um acidente de transporte [V60-V69]; Ocupante 
de ônibus traumatizado em um acidente de transporte [V70V79]; Outros acidentes de transporte terrestre [V80-V89]; Acidentes de transporte por água [V90-V94]; Acidentes de transporte aéreo e espacial [V95-V97] e Outros acidentes de transporte e os não especificados [V98-V99]. Ressalta-se que, para a análise em questão, as vítimas fatais pelas causas de Acidentes de transporte por água [V90-V94] e de Acidentes de transporte aéreo e espacial [V95-V97] foram excluídas, considerando o seu contexto de ocorrência.

0 estudo partiu da análise de variáveis demográficas como sexo (feminino e masculino) e faixa etária ( $<10$ anos crianças; 10-19 anos - adolescentes; 20-59 anos - adultos; e" 60 anos - idosos). Foi realizado o cálculo do Coeficiente de Mortalidade por 100.000 habitantes $\left(10^{5}\right)$, pela expressão Total de óbitos de residentes em certa área, no ano considerado/ População residente na área '100.000, para o período de 12 anos, e sua média anual. ${ }^{9}$

Em seguida, foram identificados os Anos Potenciais de Vida Perdidos (APVP), considerando todos os óbitos ocorridos até 80 anos. Foram calculados: o valor total de APVP para todo o período de análise, o número médio de APVP $\left(\mathrm{APVP}_{\mathrm{m}}\right)$ e o APVP padronizado (APVP105) por 100.000 habitantes. A fórmula básica para APVP utilizada foi: $A P V P=S$ ai ' di, onde: ai representa a diferença entre a idade limite e o ponto médio de cada grupo etário, pressupondo-se distribuição uniforme das mortes ocorridas em cada grupo; dié igual ao número de óbitos por uma causa específica neste mesmo grupo etário., ${ }^{9}, 12$

0 APVP $_{m}$ expressa a quantidade de anos que em média cada óbito subtraiu de uma pessoa. Foi utilizada a fórmula: APVP/ número de óbitos ocorridos devido ao mesmo tipo de causa em estudo. Já, para o APVP10 $0^{5}$, utilizou-se APVP ' 100.000. A análise dos indicadores APVPs ocorreu com intervalo de confiança de $95 \%$ e pela apresentação dos resultados em triênios. ${ }^{9,12}$

0 presente estudo foi aprovado pelo Comitê de Ética em Pesquisa da Universidade Federal do Triângulo Mineiro (UFTM), sob o número 1.651/2010, e os dados utilizados nesta pesquisa compõem o projeto "Evolução Espaço-Temporal dos óbitos por causas violentas em Minas Gerais."

\section{RESULTADO}

Tabela 1. Distribuição dos Coeficientes de Mortalidade por 100.000 habitantes por Acidentes de Transporte [CID10:V01-V99] e sua caracterização demográfica em Minas Gerais, Brasil, 1996a 2007.

\begin{tabular}{|c|c|c|c|c|c|c|c|c|c|c|c|c|c|}
\hline \multirow{2}{*}{$\begin{array}{c}\text { Dados } \\
\text { Demográficos }\end{array}$} & \multicolumn{12}{|c|}{ Período } & \multirow{2}{*}{$\begin{array}{l}\text { Média } \\
\text { Anual }\end{array}$} \\
\hline & 1996 & 1997 & 1998 & 1999 & 2000 & 2001 & 2002 & 2003 & 2004 & 2005 & 2006 & 2007 & \\
\hline \multicolumn{14}{|l|}{ Faix a Etánia(anos) } \\
\hline $\begin{array}{l}\text { Crianças } \\
<10 \text { anos }\end{array}$ & 17,14 & 15,43 & 14,60 & 12,32 & 12,73 & 13,16 & 10,00 & 11,97 & 12,62 & 12,65 & 9,49 & 12,28 & 12,84 \\
\hline $\begin{array}{l}\text { Adolescertes } \\
10-19 \text { anos }\end{array}$ & 24,98 & 20,56 & 19,56 & 18,50 & 15,38 & 16,79 & 18,38 & 17,67 & 19,67 & 19,30 & 20,50 & 22,78 & 19,48 \\
\hline $\begin{array}{c}\text { Adultos } \\
20-59 \text { anos }\end{array}$ & $\begin{array}{c}109,8 \\
5\end{array}$ & $\begin{array}{c}113,4 \\
9\end{array}$ & 97,63 & 84,54 & 75,09 & 80,57 & 85,56 & 90,62 & 99,40 & $\begin{array}{c}100,1 \\
3\end{array}$ & $\begin{array}{c}105,5 \\
3\end{array}$ & $\begin{array}{c}100,1 \\
9\end{array}$ & 95,09 \\
\hline $\begin{aligned} & \text { Idosos } \\
\geq & 60 \text { anos }\end{aligned}$ & $\begin{array}{c}107,1 \\
1\end{array}$ & 83,69 & 81,99 & 87,93 & 65,16 & 73,57 & 70,72 & 79,07 & 90,82 & 94,70 & $\begin{array}{c}104,8 \\
1\end{array}$ & 84,74 & 85,22 \\
\hline Total & 20,73 & 20,05 & 17,49 & 15,74 & 14,15 & 15,10 & 15,88 & 16,56 & 18,32 & 18,24 & 19,39 & 19,56 & 17,61 \\
\hline \multicolumn{14}{|l|}{ Sexo } \\
\hline Feminino & 8,85 & 8,65 & 7,66 & 6,32 & 5,72 & 5,82 & 6,30 & 6,30 & 6,97 & 6,91 & 7,61 & 6,78 & 6,97 \\
\hline Masculino & 32,72 & 31,60 & 27,47 & 25,34 & 22,75 & 24,58 & 25,65 & 27,03 & 29,91 & 29,81 & 31,44 & 32,62 & 28,44 \\
\hline
\end{tabular}

Tabela 2. Distribuição das características demográficas dos Anos Potenciais de Vida Perdidos (APVP) e coeficientes relacionados aos óbitos por Acidentes de Transporte [CID-10:V01-V99], Minas Gerais, Brasil, 1996 a 2007.

\begin{tabular}{|c|c|c|c|c|}
\hline \multirow[t]{2}{*}{ Período } & \multirow[t]{2}{*}{ Coeficientes - APVP } & \multicolumn{2}{|c|}{ Sexo } & \multirow[t]{2}{*}{ Total } \\
\hline & & Feminino & Masculino & \\
\hline \multirow[t]{3}{*}{$1996-1998$} & APVP & 43,80 & 44,14 & 44,06 \\
\hline & APVP/ $10^{5}$ Habitantes & 1054,33 & 3926,02 & 2479,66 \\
\hline & Idade Média do Óbito & 36,20 & 35,86 & 35,94 \\
\hline \multirow[t]{3}{*}{$1999-2001$} & APVP & 42,67 & 43,75 & 43,53 \\
\hline & APVP/ $10^{5}$ Habitantes & 732,58 & 3110,97 & 1909,73 \\
\hline & Idade Média do Óbito & 37,33 & 36,25 & 36,47 \\
\hline \multirow[t]{3}{*}{$2002-2004$} & APVP & 43,00 & 42,99 & 42,99 \\
\hline & APVP/ $10^{5}$ Habitantes & 813,31 & 3486,49 & 2136,14 \\
\hline & Idade Média do Óbito & 37,00 & 37,01 & 37,01 \\
\hline \multirow[t]{3}{*}{$2005-2007$} & APVP & 41,65 & 42,73 & 42,53 \\
\hline & APVP/ $10^{5}$ Habitantes & 850,41 & 3925,22 & 2371,26 \\
\hline & Idade Média do Óbito & 38,35 & 37,27 & 37,47 \\
\hline \multirow[t]{3}{*}{$1996-2007$} & APVP & 42,79 & 43,36 & 43,24 \\
\hline & APVP/ $10^{5}$ Habitantes & 3437,91 & 14457,61 & 8894,46 \\
\hline & Idade Média do Óbito & 37,21 & 36,64 & 36,76 \\
\hline \multirow{6}{*}{$\begin{array}{c}1996-2007 \\
\text { (IC 95\%) }\end{array}$} & APVP & 42,03 & 42,84 & 42,71 \\
\hline & & 43,54 & 43,95 & 43,83 \\
\hline & APVP/ $10^{5}$ Habitantes & 243,11 & 1016,44 & 626,99 \\
\hline & & 2512,31 & 10546,09 & 6489,50 \\
\hline & Idade Média do Óbito & 36,46 & 36,05 & 36,17 \\
\hline & & 37,97 & 37,16 & 37,29 \\
\hline
\end{tabular}


Minas Gerais é o segundo estado brasileiro em relação à mortalidade por acidentes de trânsito., ${ }^{5,7}$ No período de 1996 a 2007, as vítimas fatais por este agravo perfizeram 38.395 óbitos. Os pedestres e ciclistas vitimizados totalizaram $25,38 \%$; as vítimas fatais por acidentes entre os ocupantes de veículos automotores, 70,53\%; e os acidentes de transporte não específico, $4,01 \%$. Já o coeficiente de mortalidade apresentou média anual de 17,61 vítimas fatais para cada 100.000 habitantes por acidentes de trânsito. Os adultos foram a faixa etária mais vitimizada pelas mortes no trânsito. A média anual de óbitos por essa causa em adultos foi de 95,09/100.000 habitantes (Tabela 1).

Chama atenção o expressivo coeficiente de mortalidade por acidentes no trânsito entre os idosos. 0 grupo etário de vítimas com 60 anos e mais representou 0 segundo maior grupo de mortes por acidentes de trânsito. A mortalidade no trânsito de idosos foi 2,5 vezes maior do que a soma da mortalidade de crianças e adolescentes. Em média, por ano, ocorreu o óbito de 85,22 idosos/100.000 habitantes (Tabela 1).

A soma de coeficientes de mor talidade de crianças e adolescentes apresentou média anual de 32,32 vítimas fatais para cada 100.000 habitantes. A evolução dos óbitos no trânsito para menores de 10 anos apresentou os menores valores para os coeficientes de mor talidade. A vitimização por esse tipo de causa foi maior entre os adolescentes, com coeficiente médio de 19,48 óbitos/100.000 habitantes (Tabela 1).

Os homens foram as maiores vítimas fatais por acidentes de trânsito, sendo 4,0 óbitos masculinos para cada óbito feminino. A média anual dos coeficientes foi de 6,97 óbitos femininos em relação a 28,44 óbitos masculinos por 100.000 habitantes por acidentes de trânsito (Tabela 1).

Quanto ao impacto das mortes por acidentes de trânsito, em Minas Gerais, o cálculo do APVP demonstrou uma perda total de $8.894,46$ anos de vida/100.000 habitantes. Consequentemente, em relação ao período total de estudo, cada vítima fatal por essa causa óbito sofreu uma perda de 43,24 anos de vida. Considerando todas as variáveis e o período de análise de 1996 a 2007, 95\% das vítimas fatais por acidentes de trânsito tinham entre 36,17 e 37,29 anos. Houve discreta redução no total de APVP quando se comparou os triênios, devido ao aumento na média da idade de ocorrência desses óbitos. Na comparação trienal, observou-se aumento do indicador APVP/100.000 habitantes, em decorrência do aumento de vítimas fatais por acidentes de trânsito (Tabela 2).

A média da idade das mulheres vítimas fatais por acidentes de trânsito foram 37,21 anos e dos homens 36,64 anos. Os anos de vida perdidos para os homens foi APVP $I_{95 \%}=42,84: 43,95$ e, para as mulheres, APVP
$I_{95 \%}=42,03: 43,54$. Considerando estes resultados, houve semelhanças entre a idade do óbito e anos de vida perdidos por acidentes de trânsito em Minas Gerais, para ambos os sexos (Tabela 2).

\section{DISCUSSÃO}

0 perfil das vítimas fatais por acidentes de trânsito são convergentes em diferentes localidades nacionais e internacionais. Esse cenário aponta para a prevalência da problemática dos acidentes de trânsito entre os homens adultos. $., 8,8,13-15$

No Rio de Janeiro/RJ, registros do Instituto Médico Legal apresentaram como características demográficas para os óbitos no trânsito associados à alcoolemia $53,5 \%$ das ocorrências na faixa etária de 20 a 49 anos. ${ }^{8}$ Nas regiões Centro-Oeste e Norte, as vítimas fatais por acidentes foram $82,1 \%$ do sexo masculino, com maior concentração na faixa etária de 20 a 49 anos. ${ }^{13}$

No Brasil, ocorreram 19 óbitos para cada 100.000 habitantes, sendo que $81 \%$ desses óbitos foram masculinos e $83 \%$ se concentravam na faixa etária de 15 a 59 anos. ${ }^{14}$ Nos Estados Unidos, os acidentes de trânsito foram uma das principais causas de mortalidade entre homens da faixa etária entre 16 e 39 anos. $^{15}$

Os acidentes de trânsito constituem a segunda causa de morte precoce no mundo entre os homens, ${ }^{4}$ embora a idade das vítimas fatais no trânsito de ambos os sexos seja superior à idade dos óbitos das vítimas por demais causas externas. 4,12,14 De forma geral, as análises dos indicadores que descrevem os anos de vida perdidos, principalmente para as causas externas, permitem quantificar aspectos diferenciais na identificação da população de risco para o agravo. ${ }^{9}$

Em Salvador/BA, os óbitos por causas externas, incluindo os acidentes de trânsito, totalizaram perda de 14.507 anos potenciais de vida para cada 100 mil habitantes, e a média de idade das vítimas fatais de trânsito foi superior a das vítimas por demais causas externas, aos 30,3 anos. ${ }^{12}$ Além disso, as vítimas fatais por acidentes de trânsito apresentaram média de idade de 35,5 anos, ${ }^{12}$ valor semelhante às médias identificadas no presente estudo, em Minas Gerais.

As características comportamentais determinam a vulnerabilidade do grupo populacional, considerando que os homens adultos assumem maiores riscos na condução de veículos, pois apresentam maior consumo de bebidas alcoólicas e realizam maior número de manobras imprudentes no trânsito. ${ }^{5,8,15}$

Ao se considerar os aspectos do dinamismo social atual, a circulação de bens e o contingente populacional contribuem para a prevalência do perfil das vítimas fatais por acidentes de trânsito. Observa-se que as áreas produtivas, aquelas que absorvem a força de trabalho, estão localizadas, em sua maioria, em regiões distantes das áreas habitacionais. Essa 
realidade exige o deslocamento cotidiano de grandes massas populacionais. Tendo em vista a maior consolidação do sexo masculino no mercado produtor em relação ao sexo feminino, perfazendo para os homens adultos a maior força de trabalho produtiva, é esperado que esse grupo esteja mais vulnerável aos acidentes de trânsito., 5,6

Outra característica evidenciada pelos resultados quanto ao perfil das vítimas fatais está relacionada ao aumento da mortalidade entre os idosos. No Brasil, os coeficientes de mortalidade por acidentes de trânsito para as pessoas com 60 anos e mais são mais elevados do que o coeficiente para a população geral. ${ }^{14}$ Entre as três capitais brasileiras, São Paulo/ SP, Rio de Janeiro/RJ e Porto Alegre/RS, os coeficientes de mortalidade por acidentes de trânsito foram impactantes para a população idosa, com destaque para aqueles com 80 anos e mais, sendo a soma dos coeficientes, entre 2005 e 2007, de 378 óbitos, 399 óbitos; 356 óbitos, todos por 100.000 habitantes, respectivamente. ${ }^{6}$

No Canadá, a morte de idosos por acidentes de trânsito superam as morte dos adolescentes. ${ }^{15}$ Nos Estados Unidos, a ocorrência de acidentes fatais com condutores de 80 anos e mais foi 9,0 vezes maior quando comparada a de condutores entre 25 e 69 anos. ${ }^{16}$

Aliás, o aumento da ocorrência de acidentes de trânsito entre os idosos é decorrente, principalmente, da transição demográfica. De certa forma, a elevação da expectativa de vida populacional tem contribuído para 0 aumento do número de idosos condutores de veículos automotores. Entretanto, as características da senilidade, como a redução da capacidade psicomotora e da acuidade visual, associadas à utilização de medicamentos ou às sequelas de outras doenças, têm trazido outras dificuldades para a condução efetiva de veículos. ${ }^{6,7,15-17}$

Um estudo com 1.425 idosos condutores habitantes de Winsconsin/USA, entre 67 a 87 anos, evidenciou dificuldade desses condutores em parar o veículo mediante solicitação de sinais de trânsito. ${ }^{16}$ Diante dessa realidade, foram necessárias intervenções diferenciadas, como aquela estabelecida no Flórida/USA, onde todos os cidadãos com 80 anos ou acima são avaliados por exames de maior acurácia para mensuração da acuidade visual, para manter-se com a licença de condutor, fato que resultou na redução de óbitos no trânsito, desde 2004. ${ }^{17}$

Por outro lado, além do aumento do número de condutores, houve o aumento da circulação de pedestres idosos. ${ }^{16}$ No território nacional, $48,2 \%$ das vítimas fatais por acidentes de trânsito com 60 anos e mais foram pedestres. ${ }^{14}$ Observa-se que as vulnerabilidades inerentes a essa faixa etária contribuem para a elevada letalidade nos acidentes de trânsito, haja vista que 0 atropelamento de idosos pedestres se caracteriza como um dos acidentes mais violentos, provocando lesões graves independente da velocidade da colisão. ${ }^{6,7,15-17}$
Diante dos resultados, vale ressaltar que a prevalência dos elevados coeficientes de mortalidade por acidentes de trânsito entre os homens adultos e o seu crescente aumento entre os idosos se respaldam em atitudes de desrespeito dos condutores com a legislação de trânsito e também pela precariedade da infraestrutura do sistema de tráfego. ${ }^{5-8}$

Por mais que as mortes por causas externas, incluindo os acidentes de trânsito, sejam mais informadas do que outras causas de óbito, é preciso atentar para a qualidade dos registros. De um modo geral, as informações estão relacionadas com o preenchimento correto das declarações de óbito pelos médicos e sua adequada alimentação na plataforma operativa do sistema de informação, por técnicos e codificadores. A falta de treinamento e de supervisão dos profissionais durante esses processos resulta em perdas de dados, como o envio de relatórios com campos incompletos ou ignorados. $7,9,13,14$

Quanto à realização de pesquisas epidemiológicas com utilização de dados secundários, é inegável a sua contribuição; entretanto, é preciso destacar as suas limitações, enquanto fonte de dados. 0 Sistema de Informação sobre Mortalidade (SIM) é de abrangência nacional, desenvolvido pelo DATASUS, pelo qual são consolidadas todas as declarações de óbito emitidas pelos profissionais médicos. Esses registros são considerados as fontes mais ágeis na enumeração e quantificação dos acidentes, ao ponto de subsidiarem informações para o planejamento das ações dos serviços de saúde. ${ }^{7,9,13,14}$

Nesse sentido, mesmo diante dos esforços nacionais para o controle e redução dos acidentes de trânsito e sua mortalidade, com a promulgação do Código de Trânsito Brasileiro (CTB) em $1997^{18}$ e a Política Nacional de Redução da Morbimortalidade por Acidentes de Violências em 2001', ainda há muito o que fazer pelo setor saúde, incluindo as ações de enfermagem, nas abordagens desse agravo, seja na busca da qualidade da assistência a ser prestada ou nas atividades de prevenção e promoção da saúde.

\section{CONSIDERAÇÕES FINAIS}

Em Minas Gerais, a maioria das vítimas fatais por acidentes de trânsito concentrou-se na faixa etária de 20 a 59 anos. 0 coeficiente de mortalidade para a faixa etária de 60 anos e mais apresentou ascendência. Os óbitos infanto-juvenis, até 19 anos, corresponderam à terceira faixa etária de maior prevalência de óbito.

Os acidentes de trânsito fatais foram mais prevalentes no sexo masculino, sendo expressivos nos homens; para cada vítima fatal feminina ocorreram 4,0 óbitos masculinos. Houve perda, em média de 43,24 APVP. Na comparação trienal, observou-se um aumento dos valores da média da idade dos óbitos e dos APVPs/100.000 habitantes. 
0 perfil das vítimas fatais dos acidentes de trânsito convergem em diferentes localidades brasileiras e internacionais. Mesmo diante da ascensão dos coeficientes de mortalidade por acidentes de trânsito em idosos, o perfil das vítimas fatais continua sendo do sexo masculino e de faixa etária adulta produtiva, cujo contexto social se caracteriza pelo transporte de bens e serviços, evidenciando de forma lamentável, para a sociedade mundial, o ônus causado pela perda destas pessoas em idade produtiva.

A prevalência de óbitos por acidentes de trânsito apresenta-se no cenário atual da saúde e para a enfermagem brasileira como um problema extremamente complexo, e para o seu enfrentamento são necessárias abordagens articuladas com os diferentes setores sociais, e intervenções criativas. Por esta razão, é preciso ampliar a compreensão sobre esta temática, disseminar a importância da prevenção de acidentes e buscar juntamente, com os diversos segmentos da sociedade, as formas de resgatar a responsabilidade que cada cidadão brasileiro deve ter para com a vida do outro.

\section{REFERÊNCIAS}

1.Portaria MS/GM n. ${ }^{0} 737$, de 16 de maio de 2001. Política Nacional de Redução da Morbimortalidade por Acidentes e Violências. Diário Oficial da União República Federativa do Brasil, Brasília (DF), n. 96, 18 de maio de 2001, Seção 1 E.

2.Minayo MCS, Souza ER. Violência sob o olhar da saúde: a infra-política da contemporaneidade brasileira. Rio de Janeiro: Ed Fiocruz; 2003.

3.Fonseca RMG, Egry YE. Epidemiologia Social. In. Garcia TR, organizadora. Integralidade da atenção no SUS e sistematização da assistência de enfermagem.São Paulo: Artmed. 2010. p.78-108.

4.World Health Organization-WHO. World report on road traffic injury prevention. Geneva; 2004.

5.Bernardino AR. Especialização dos acidentes de trânsito em Uberlândia (MG): técnicas de geoprocessamento como instrumento de analise 2000 a 2004 [tese]. São Paulo: Universidade de São Paulo; 2007.

6.Luizaga CTM. Mortalidade masculina no tempo e no espaço [dissertação de mestrado]. São Paulo: Faculdade de Saúde Pública, Universidade de São Paulo; 2010.

7.Gomes LMX, Barbosa TLA, Caldeira AP. Mortalidade por causas externas em idosos em Minas Gerais, Brasil. Esc Anna Nery. 2010 out/dez; 14(4): 779-86.

8.Abreu AMM, LIMA JMB, Griep RH. Acidentes de trânsito e a frequência dos exames de alcoolemia com vítimas fatais na cidade do Rio de Janeiro. Esc Anna Nery. 2009 mar; 13(1): 44-50.

9.Medronho RA. Estudos ecológicos. In: Medronho RA, et al. Epidemiologia. São Paulo: Atheneu, 2009. p.265-74.
10.Ministério da Saúde (BR). DATASUS. [base de dados na internet]. Informações de Saúde. Sistema de Informações sobre mortalidade. Brasília(DF); 2010 [ citado 2010 out 15]. Disponível em: http// tabnet.datasus.gov.br

11.Organização Mundial de Saúde-OMS.Centro Brasileiro de Classificação de Doenças em Português. Classificação estatística internacional de doenças e problemas relacionados à saúde. 10ª rev. São Paulo: EDUSP; 1998.

12.Araújo EM, Costa, MCN, Hogan VK, Mota ELAM, Araújo TM, Oliveira NF. Diferenciais de raça/cor da pele em anos potenciais de vida perdidos por causas externas. Rev Saude Publica. 2009 maio/jun; 43(3): 405-12.

13.Duarte EC, Duarte E, Sousa MC, Tauil PL, Monteiro RA. Mortalidade por acidentes de transporte terrestre e homicídios em homens jonvens das capitais das regiões Norte e Centro-Oeste do Brasil, 1980 a 2005. Epidemiol Serv Saude. 2008 jan/mar; 17(1): 7-20.

14.Souza MFM, Malta DC, Conceição GMS, Silva MMA, Gazal-Carvalho C, Morais Neto OL. Análise descritiva e de tendência de acidentes de transporte terrestre para políticas sociais no Brasil. Epidemiol Serv Saude. 2007; 16 (1): 33-44.

15.MacDonald N, Hébert PC. Driving retirement program for seniors: long overdue. CMA [periódico on-line]. 2010 abr; [citado 2010 set 25]; 182(7):645. Disponível em: http://www.cmaj.ca/cgi/reprint/182/7/645.

16.Keay L, Jasti S, Munoz B, Turano KA, Munro C, Duncan DD, et al. Urban and rural differences in older drivers' failure to stop at stop-signs. Accid Anal Prev. 2009 set; 41(5): 995-1000.

17.McGwin G, Sarrels SA, Griffin R, Owsley C, Rue LW. The impact of a vision screening law on older driver fatality rates. Arch Ophthalmol. 2008 nov; 126(11): 1544-547.

18. Lei $n^{\circ} 9503$, de 23 de setembro de 1997. Dispões sobre a regulamentação do Código de Trânsito Brasileiro. Diário Oficial da República Federativa do Brasil, Brasília(DF), 24 set 1997: Seção 1. 